\title{
GI2. DOES LABELLING AND PACKAGING DESIGN AFFECT EFFICIENCY AND SAFETY OF VACCINE?
}

Gisele Corrêa Miranda; Paulo Roberto Gomes dos Santos²; Patricia Soares Pereira da Silva ${ }^{3}$; Thiago Sturiale ${ }^{4}$; Ricardo Creton Altino ${ }^{5}$.

${ }^{1}$ Bio-Manguinhos / Fiocruz;

${ }^{2}$ Assessoria Clínica de Bio-Manguinhos / Fiocruz;

${ }^{3}$ Assessoria de Assuntos Regulatórios de Bio-Manguinhos / Fiocruz;

${ }^{4}$ Departamento de Relações com o Mercado de Bio-Manguinhos / Fiocruz;

${ }^{5}$ Assessoria de Engenharia Industrial de Bio-Manguinhos / Fiocruz.

INTRODUCTION According to the World Health Organization (WHO), globally almost $30 \%$ of medication errors with vaccines are related to information presented in labels and packaging, which have been ignored or misinterpreted and led to inappropriate use. This information shows the importance of labelling and packaging design in promoting rational use of medicines, considering ergonomic and visual aspects. Despite the increasing trends in differentiation and identification of medicines, the Brazilian National Regulatory Agency has published the Resolution RDC21/2012 with a Visual Identity Guide for the medicines distributed by public health programs. The impact of these changes has been evaluated by the multidisciplinary team of Community of Practice on Packaging and Logistics at Bio-Manguinhos/Fiocruz (CoP-PackLog).

OBJECTIVE This project aims to present a critical analysis of the Medicines Visual Identity Guide (Resolution RDC21/2012), in correspondence to good design labelling and packaging practices for parenteral drugs.

METHODOLOGY Due to the inexistence of an official guide to good labelling and packaging design practices, a comprehensive literature search has been performed in organized civil societies, PubMed and WHO portal in order to consolidate the best practices. A semi-structured interview has been applied to the pharmacist managers at the National Institute of Infectious Diseases Evandro Chagas. Both strategies have focused on medication errors related to labeling and packaging. These informations have been systematically compiled into a matrix used to perform the critical analysis of the RDC 21/2012. 
RESULTS A significant number of publications was found in the systematic literature review connecting labelling and packaging design to unintended failure in the drug treatment process that leads to, or has the potential to lead to, harm to the patient. The most comprehensive document indicating the best practices for vaccine packaging design is the Guidelines for the Labeling of Vaccines issued by the WHO in 2013. Based on the literature review and the WHO Guideline, it was possible to consolidate a matrix with the most relevant topics of the vaccine packaging graphic design that can affect the safety for the patient. This matrix was validated and completed by an interview with an user of vaccines in the field. With this matrix, it was possible to perform the critical analysis of RDC 21/2013, identifying compliance and divergence issues, critically evaluating and integrating them to medication errors. Mistakes in the prescribing, dispensing, storing, preparation and administration of a medicine are the most commom preventable cause of undesired adverse events in medication practice and present a major public health burden.

CONCLUSION As expected, the fragility in the adoption of the current Medicines Visual Identity Guide published under Resolution 21/2012 in the context of vaccines safety has been confirmed. Publicize the matter at hand raises awareness and contribute to the improvement of regulation and promoting rational use of medicines.

KEYWORDS vaccines, good labeling and packaging design practices, medication errors. 